\title{
Editorial: Cognitivist and ecological approaches to sports skills acquisition, development and assessment
}

\author{
RODRIGO AQUINO'1 | JOÃO C. MACHADO² | GIBSON PRAÇA ${ }^{3}$ | FILIPE M. CLEMENTE ${ }^{4,5}$ | LUIZ H. P. VIEIRA
}

\footnotetext{
1 LabSport, Department of Sports, Center of Physical Education and Sports, Federal University of Espírito Santo, Vitória, ES, Brazil.

2 Human Performance Laboratory (LEDEHU), Faculty of Physical Education and Physiotherapy, Federal University of Amazonas, Manaus, AM, Brazil.

${ }^{3}$ Sports Department, Universidade Federal de Minas Gerais, Belo Horizonte, MG, Brazil.

${ }^{4}$ Escola Superior Desporto e Lazer, Instituto Politécnico de Viana do Castelo, Viana do Castelo, Portugal.

5 Instituto de Telecomunicações, Delegação da Covilhã, Lisboa, Portugal.

${ }^{6}$ Human Movement Research Laboratory (MOVI-LAB), School of Sciences, Graduate Program in Movement Sciences, Physical Education Department, São Paulo State University (UNESP), Bauru, SP, Brazil.
}

Correspondence to: Rodrigo Aquino, PhD. Center of Physical Education and Sports, Federal University of Espírito Santo, Av. Fernando Ferrari, 514 - Goiabeiras, Vitória/ES, CEP 29075-910, Brazil. Phone: +55 16 99195-0494.

email: aquino.rlq@gmail.com

https://doi.org/10.20338/bjmb.v14i5.227

\author{
ABBREVIATIONS \\ FUT-SAT System of Tactical Assessment in \\ Football \\ TSAP Performance Assessment in Team \\ Sport
}

PUBLICATION DATA

Received 01112020

Accepted 04112020

Published 01122020

In everyday life and sport settings, individuals coordinate their movements to achieve task goals like passing the ball in soccer and executing tactical principles during individual and team sports. This ability to coordinate actions individually, with teammates and/or opponents, is often critical to success in sport. ${ }^{1}$ The cognitivist approach involves the idea of cognitive science, which considers that performance is predicated on the existence of representation or schema, responsible for organization and regulation of behaviors (i.e., the brain's role based on information-processing theory). ${ }^{2}$ In the last years, the fast development of technologies led to improvements in our knowledge of central functioning (e.g., brain activity) during skills acquisition, development, and assessment, such as using functional magnetic resonance imaging and mobile EEG. ${ }^{3}$ Instead, ecological psychology theories are not too much interested in cognition and focus on the available information constraints that afford individuals' perception and action. ${ }^{4}$ From this perspective, the emergence of coordinated behaviors in skills acquisition, development, and assessment is based on the emergence of interpersonal synergies between individuals resulting from collective actions predicated on possibilities for actions (affordances). ${ }^{5}$ The two aforementioned approaches differ in their fundamental ideas. They are opposed to the action's explanations, but sometimes can be complementary to each other. A rich combination of issues related to these approaches to sports skills acquisition, development, and assessment is presented by four articles in this special topical collection of the Brazilian Journal of Motor Behavior.

Firstly, Rodrigues, Gotardi, Polastrib sought to emphasize theoretical assumptions

\begin{tabular}{l|l|l|l|ll}
\hline Aquino et al. & 2020 & VOL.14 & N.5 & https://doi.org/10.20338/bjmb.v14i55227
\end{tabular}


of visual perception through both cognitivist and ecological approaches and highlights the ecological dynamics as an important framework to understand sport skills. Thus, the authors highlighted the main concepts of Direct and Indirect Theories, discussing the main differences of these two theories regarding the following topics: optical array and retinal image; immediate and mediate perception; affordances and representations. After the authors highlighted an attempt to combine cognitivist and ecological perspectives, they sought to support ecological dynamics framework to understand decision-making in the sports context. Therefore, this first paper brought important theoretical discussions about cognitivist and ecological approaches that support assumptions of decision-making and skills acquisition in sport.

Next, Petiot, Silva, Ometto ${ }^{7}$ discussed the importance of three key tactical competencies in team sports: tactical intelligence, creativity, and co-adaptability. The first refers to the ability to find suitable decisions for emerging problems during the game. Creativity refers to exploring innovative possibilities to solve those emerging problems, so involving all aspects of tactical intelligence. Finally, co-adaptation relies on the players' adapt and collectively coordinate actions in a constantly changing environment. The authors also discussed those three concepts in terms of pedagogical strategies to nurture their development. At this point, game-based tasks, such as the small-sided games, may be potentially useful for developing all three competencies as they can provide players with an environment, which requires constant exploration for solutions. Hence, coaches must pay special attention to designing adequate tasks to nurture players' intelligence, creativity, and co-adaptation in team sports.

Following this conceptual discussion, Ribeiro, Garganta, Davids, Barreira ${ }^{8}$ made an introduction and brief appraisal of the use of hyper networks metrics and its potential practical application in examining team dynamics' coordination patterns collective sports. Throughout their critique piece, the authors highlighted that game analysis, including the hyper network concept, may help overcome the limitations of previous tools such as social network measures. For example, while the social network analysis generally considers only dyadic interactions (e.g., between two players), the hyper networks also take into account a multidimensional perspective, including both player level and team level communication and coordination. However, given the relative lack of evidence on this new research topic addressed by Ribeiro and collaborators (2021), the authors also evidenced that new studies using hyper network metrics are required in a range of team sports, mainly using data gathered from official competition matches.

Finally, Júnior, Aquino, Machado ${ }^{9}$ analyzed the relationships between the results obtained from two observational systems in under-11 players: Performance Assessment in Team Sport (TSAP) and System of Tactical Assessment in Football (FUT-SAT). Considering each instrument's different purposes, the results of this original study revealed no meaningful correlations between performance indicators provided by both instruments. Additionally, when the instruments were used to classify the players, both revealed different ranks for the players. These findings highlighted that both instruments should be used for different objectives, namely FUT-SAT for helping coaches to monitor tactical principles of players, while TSAP should be used for analyzing technical/tactical actions.

The multiplicity of contents presented in this special edition and other journals illustrates the growing interest of sports scientists and practitioners to better understand the ecological and cognitivist approaches applied in sports settings. However, a common 
problem in sports science is the lack of interaction between areas and knowledge disciplines. We cannot consider a one size fits all approach for a global understanding of the acquisition, development, and assessment process in sport. The human action during sports practice (so complex!) can be better understood including different approaches based on interactionism theories (e.g., cognitivist, constructivist, ecological, socio-cultural) and disciplines of knowledge, for instance, motor behavior, sports pedagogy, sports training, sports biomechanics, and sports sociology as well as from micro to macro-level of analysis. ${ }^{10}$

\section{REFERENCES}

1. Silva P, Garganta J, Araújo D, Davids K, Aguiar P. Shared knowledge or shared affordances? Insights from an ecological dynamics approach to team coordination in sports. Sports Med. 2013; 43(9):765-772. doi: 10.1007/s40279-013-0070-9

2. Davids $K$, Handford $C$, Williams $M$. The natural physical alternative to cognitive theories of motor behaviour: An invitation for interdisciplinary research in sports science? J Sports Sci. 1994; 12(6):495-528. doi: 10.1080/02640419408732202

3. Jorgenson LA, Newsome WT, Anderson DJ, et al. The BRAIN Initiative: developing technology to catalyse neuroscience discovery. Philos Trans R Soc Lond B Biol Sci. 2015; 370(1668):20140164. doi: 10.1098/rstb.2014.0164

4. Gibson JJ. The ecological approach to visual perception: classic edition, Psychology Press; 2014.

5. Araújo D, Davids K. Team synergies in sport: theory and measures. Front Psychol. 2016; 7:1449. doi: 10.3389/fpsyg.2016.01449

6. Rodrigues ST, Gotardi GC, Polastri PF. Understanding sport skills through the theories of visual perception: Contrasting cognitive and ecological approaches. Braz J Mot Behav. 2020; 14(5): 141-156. doi: 10.20338/bjmb.v14i5.221

7. Petiot GH, Silva D, Ometto L. Exploring key competencies sought to potentialize tactical behavior in soccer players. Braz J Mot Behav. 2020; 14(5): 157-166. doi: 10.20338/bjmb.v14i5.199

8. Ribeiro J, Garganta J, Davids K, Barreira D. A multilevel hypernetworks approach to assess coordination and communication in player interactions in sports teams as coevolutionary networks. Braz J Mot Behav. 2020; 14(5): 167-170. doi: 10.20338/bjmb.v14i5.216

9. Júnior JAS, Aquino R, Machado JC. Tactical performance in soccer: The importance of choosing and properly applying tactical assessment tools. Braz J Mot Behav. 2020; 14(5): 171-179. doi: 10.20338/bjmb.v14i5.210

10. Tani G. Motor Behavior and its relationship with Physical Education. Braz J Mot Behav. 2006; 1(1):20-31. doi: 10.20338/bjmb.v1i1.4 
Citation: Aquino R, Machado JC, Praça G, Clemente FM, Vieira LHP. Editorial: Cognitivist and ecological approaches to sports skills acquisition, development and assessment. BJMB. 2020: 14(5): 137-140.

Editors: Dr Fabio Augusto Barbieri - São Paulo State University (UNESP), Bauru, SP, Brazil; Dr José Angelo Barela São Paulo State University (UNESP), Rio Claro, SP, Brazil; Dr Natalia Madalena Rinaldi - Federal University of Espirito Santo (UFES), Vitória, ES, Brazil.

Guest Editors: Dr Rodrigo Aquino - Federal University of Espírito Santo (UFES), Vitória, ES, Brazil; Ms Luiz H Palucci Vieira - São Paulo State University (UNESP), Bauru, SP, Brazil; Dr Filipe Manuel Clemente - Escola Superior Desporto e Lazer, Instituto Politécnico de Viana do Castelo, Melgaço, Portugal; Dr João Cláudio Braga Pereira Machado -Federal University of Amazonas (UFAM), Manaus, AM, Brazil; Dr Gibson Moreira Praça - Universidade Federal de Minas Gerais (UFMG), Belo Horizonte, MG, Brazil.

Copyright:@ 2020 Aquino, Machado, Praça, Clemente and Vieira and BJMB. This is an open-access article distributed under the terms of the Creative Commons Attribution-Non Commercial-No Derivatives 4.0 International License which permits unrestricted use, distribution, and reproduction in any medium, provided the original author and source are credited.

Funding: This research did not receive any specific grant from funding agencies in the public, commercial, or not-forprofit sectors.

Competing interests: The authors have declared that no competing interests exist.

DOl: https://doi.org/10.20338/bjmb.v14i5.227 